\section{Gaps loom in satellite data}

\section{London}

CURRENT plans to monitor the global climate and stratospheric ozone depletion by satellite leave yawning gaps in the collection of key datasets, according to leading atmospheric scientists. As a result, the world's governments may be 'flying blind' - deprived of a continuous record of the environmental changes that they are striving to control - as they struggle to build and enforce international treaties to limit global change.

Officials on both sides of the Atlantic are aware of the problem. Last week, leading atmospheric scientists descended on Washington to argue the case for a series of new environmental monitoring satellites, to be launched in the mid-1990s. British officials are leading a drive to improve the international coordination of satellite launches, to prevent existing data gaps from widening still further.

But the gaps cannot be removed altogether without new satellites. And with most of the world's space agencies feeling a financial squeeze, some interruptions in the flow of data seem inevitable.

David Fisk, chief scientist at the UK Department of the Environment, says that a large gap in the satellite monitoring of stratospheric ozone depletion is likely to open in 1995, when the US-led Upper Atmosphere Research Satellite (UARS) stops functioning. Researchers had hoped that UARS would be followed by a similar German satellite called ATMOS. But Arndt Langner, head of Earth observation at DARA, the German space agency, says that Germany has "nearly given up" on its plans for ATMOS because of budget problems. Instead, he says, the agency is concentrating on salvaging some of the ATMOS instruments for later missions planned by the European Space Agency.

This leaves a three-year gap until the earliest possible launch of a similar satellite, as part of the international Earth $\mathrm{Ob}$ serving System (EOS). But the latest plan for EOS from the US National Aeronautics and Space Administration (NASA) would delay further the first launch of instruments to monitor changes in stratospheric ozone. NASA is making ready plans that call for the launch of the EOS atmospheric chemistry experiments in 2000 and 2002, rather than the original timetable of 1998.

Mark Schoeberl, an atmospheric physicist from NASA's Goddard Space Flight Center in Maryland, says that the gaps in data coverage are a serious concern. Other satellites will be carrying Total Ozone Mapping Spectrometers, which measure the total amount of ozone in the column of atmosphere beneath a satellite, he says. But Schoeberl says it is also important to record in detail the chemical changes oc- curring in the stratosphere - data that ATMOS and the instruments originally due for launch in 1998, as part of EOS, would have provided. "Without a little more detail, it's very difficult to determine what's going on," he says.

The situation for climate monitoring is in many ways worse, largely due to the sheer complexity of the system that climatologists wish to monitor. Again, EOS will provide valuable data, but many researchers argue that there is also a need for a suite of 'cheap and cheerful' satellites to provide baseline data. Most of the instruments planned for EOS are designed for "diagnostic" studies into processes affecting the climate, rather than the basic job of climate monitoring.

\section{IMAGE UNAVAILABLE FOR COPYRIGHT REASONS}

\section{What will fill the void when UARS dies?}

One major component of this less-glamorous task is to produce a continuous record of the Earth's radiation balance. But again, there are gaps in data coverage. There is now no instrument in orbit to monitor in detail the influence of clouds on the radiation balance, after the 1990 failure of a scanner on the US Earth Radiation Budget Satellite (ERBS).

Bruce Barkstrom, from NASA's Langley Research Center in Hampton, Virginia, says that a similar scanner may fly in 1995 on a joint mission between France and Russia. But even if the impoverished Russian space programme is able to launch the satellite as planned - which is far from certain - Barkstrom says the instrument is of a subtly different design. The difference, he says, will make it difficult to distinguish real changes in the Earth's radiation balance from differences in the behaviour of the two instruments.

To address the problem, Barkstrom is proposing that the United States should launch a small satellite in 1995, carrying an instrument similar to that which flew on ERBS. He presented his plan in Washington last week to the federal Committee of Earth and Environmental Sciences, a body comprising officials from all the US government agencies interested in environmental research. The committee was also briefed by James Hansen, from NASA's Goddard Institute for Space Studies in New York, on a proposal to launch a sequence of small climate monitoring satellites, or Climsats.

Hansen's idea is to monitor a range of climate parameters using a small number of tried-and-tested instruments. The first Climsat could be launched for as little as $\$ 80$ million, and replacement copies could be launched every five years at $\$ 40$ million each.

But NASA has little money to put into new satellite programmes. Shelby Tilford, NASA's director of Earth science, accepts that the agency's current climate monitoring programme "doesn't do everything. The budget doesn't permit that," he says. But he says that NASA is trying to persuade the Department of Energy - which may have some money available in its 1993 budget - to support Barkstrom's proposal for a small radiation satellite.

With little money to spend on new satellites themselves, British officials are trying to prevent any widening of the gaps in data coverage that are now opening up by improving coordination among the various nations that are planning to fly environmental satellites. John Major, the UK prime minister, has described the British concerns in a letter to the other leaders of the G-7 nations. Major suggested that the problem could be addressed at a meeting of the Committee on Earth Observations Satellites (CEOS), to be held in London in late April.

The committee was originally an offshoot of the G-7, but its membership now includes most of the countries with an interest in remote-sensing satellites. The British would like this year's annual CEOS meeting to follow a meeting of the principal users of environmental monitoring satellite data. Once the scientists have outlined their requirements, officials from the major satellite agencies could discuss how to juggle their launch plans to provide the best possible data coverage.

The British plan seems to have been well received, at least in the United States. "I wouldn't like to characterize the current level of coordination as inadequate," says Peter Backlund, NASA's assistant director for Earth science, "but you can always do better".

Many environmental scientists are more sceptical, however. They point out that no amount of international coordination can replace satellites that have been delayed or cancelled.

Peter Aldhous 